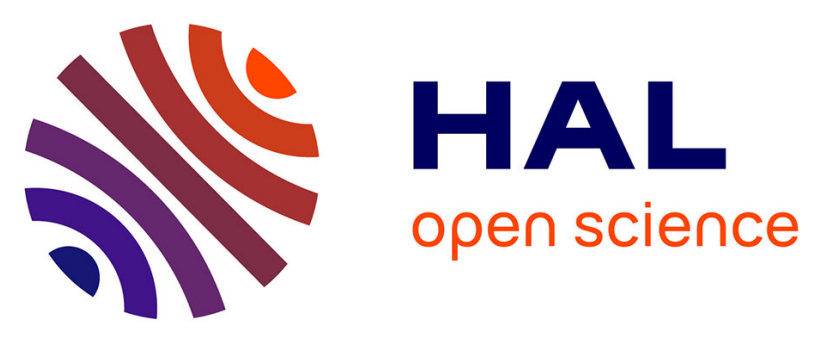

\title{
DIALOGIC/AUTHORITATIVE DISCOURSE AND MODELLING IN A HIGH SCHOOL TEACHING SEQUENCE ON OPTICS
}

\author{
Christian Buty, Eduardo Mortimer
}

\section{- To cite this version:}

Christian Buty, Eduardo Mortimer. DIALOGIC/AUTHORITATIVE DISCOURSE AND MODELLING IN A HIGH SCHOOL TEACHING SEQUENCE ON OPTICS. International Journal of Science Education, 2008, 30 (12), pp.1635-1660. 10.1080/09500690701466280 . hal-00513346

\author{
HAL Id: hal-00513346 \\ https://hal.science/hal-00513346
}

Submitted on 1 Sep 2010

HAL is a multi-disciplinary open access archive for the deposit and dissemination of scientific research documents, whether they are published or not. The documents may come from teaching and research institutions in France or abroad, or from public or private research centers.
L'archive ouverte pluridisciplinaire HAL, est destinée au dépôt et à la diffusion de documents scientifiques de niveau recherche, publiés ou non, émanant des établissements d'enseignement et de recherche français ou étrangers, des laboratoires publics ou privés. 


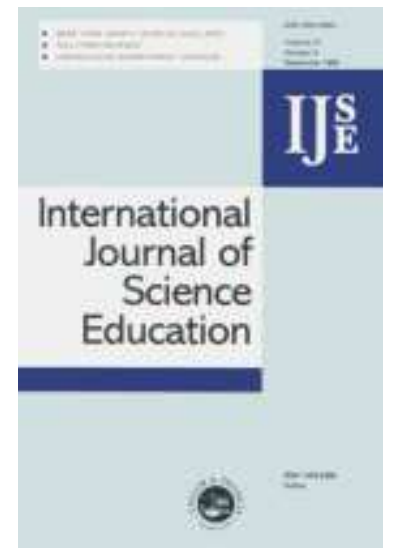

\section{DIALOGIC/AUTHORITATIVE DISCOURSE AND MODELLING IN A HIGH SCHOOL TEACHING SEQUENCE ON OPTICS}

\begin{tabular}{|r|l|}
\hline Journal: & International Journal of Science Education \\
\hline Manuscript ID: & TSED-2006-0328.R1 \\
\hline Manuscript Type: & Research Paper \\
\hline Keywords: & $\begin{array}{l}\text { qualitative research, model-based learning, physics education, } \\
\text { discourse, high school }\end{array}$ \\
\hline Keywords (user): & \\
\hline
\end{tabular}

\section{5) ScholarONE \\ Manuscript Central}




\title{
DIALOGIC/AUTHORITATIVE DISCOURSE AND MODELLING IN A HIGH
}

\section{SCHOOL TEACHING SEQUENCE ON OPTICS}

\begin{abstract}
In this paper we aim at establishing a link between two theoretical frames: modelling and its use in the design and analysis of scientific teaching sequences, and the communicative approaches as they alternate in classroom activities. In this case study, we follow the interactions between the teacher and a pair of students during an entire teaching sequence in Optics (grade 11). We focus on the way the teacher managed the dialogicity and the modelling processes in the classroom discourse. A qualitative analysis shows some difficulties in such an achievement, and their consequences on students' meaning making.
\end{abstract}

\section{Introduction}

Recent years have seen a gradual development of interest in studies of how meanings are developed through language and other modes of communication in science classrooms (for example, Lemke 1990; Sutton, 1992; Ogborn, Kress, Martins \& McGillicuddy 1996; Roychoudhury \& Roth 1996; Mortimer, 1998; Scott, 1998; Candela, 1999; Kress, Jewitt, Ogborn \& Tsatsarelis 2001; Kelly \& Brown 2003; Mortimer \& Scott 2003).

Another recent trend in science education research is the increasing prominence of studies of modelling processes (for example Grosslight, Unger, Jay \& Smith 1991; Tiberghien, 1994; Devi, Tiberghien, Baker \& Brna 1996; Gilbert \& Boulter, 1998; Gobert \& Buckley, 2000; Treagust, Chittleborough \& Mamiala 2002; Besson \& Viennot, 2004) and the development of this for teachers' professional development (Justi \& Gilbert, 2002; Crawford \& Cullin, 2004). In this paper we bring together these two areas of research by addressing some questions concerning the ways in which dialogic discourse might help students to understand modelling 
processes. We are also interested in investigating whether teaching activities explicitly based on modelling processes favour the emergence of dialogic discourse in the classrooms. In analyzing some episodes from a teaching sequence on Optics for 16/17 year-old French students (grade 11), we draw on some aspects of the analytical framework proposed by Mortimer and Scott (2003) and also on the conception of modelling proposed by Buty, Tiberghien and Le Maréchal (2004).

\section{Theoretical Background}

In this section, we will present the main features of the two theoretical frames we are going to use, on modelling and on discursive interactions.

\section{Modelling processes}

\section{Epistemological point of view}

From an epistemological point of view, science is a cognitive activity focused on thinking about a given domain of the physical world, with the aim of explaining it, and predicting the possibility of events and the consequences of actions we might carry out in this world. For these purposes, it is necessary to establish models. 'Like other metascientific concepts, the notion of model defies formal definition. One might say, perhaps, that a theoretical model is an abstract system used to represent a real system, both descriptively and dynamically' (Ziman, 2001: 147). Ziman argues that models are never constructed from direct perceptions, but from pre-existing theories, which orient our perceptions by providing the theoretical 'lens' that makes the perceived world meaningful. When constructing the "abstract system", some elements of the "real system" are forgotten, and some are modified or described according to the theory which is chosen to elaborate the model.

Using models is a continuous activity of scientists. This is an aspect of science which can be considered as solved within the frame of 'normal science', and scientists, in the course of their professional activity, feel 'an characteristic unconcern' (Kuhn, 1970: 47) for analyses of this 
kind. It has not always been the case. Looking backwards in the history of science, we can observe that one of the basic distinctions Science made from the birth of modern science what Kant called the Copernican revolution - was that between the subject matter and the object of study. Galileo, for example, was not able to study a 'real' pendulum. He had to detach his pendulum from the real world in order to make it an object of study. Science cannot study the real world as it is; it has to simplify it in order to be able to model it. It has to separate the object or phenomenon of interest from all the complexities that cannot be handled within a theoretical framework.

We can observe too that scientists do reflect on the epistemological status of models each time a revolution in science occurs ('when the normal-scientific tradition change[s]', Kuhn, 1970: 112), because a revolution generally leads to a new way of seeing the world. A major change of this sort happened, for example, when Newton proposed a new way of seeing the world in which all the objects on Earth behave in the same way as the planets and stars in the universe.

\section{Educational point of view}

Very often, science teachers do not appear to see the necessity of making explicit the distinction between the "abstract system" (the model) and the "real system", during science instruction. They neither spend a lot of time to describe the way the model has been established, under the control of a given theory.

On the contrary we, as researchers in science education, consider that an explicit epistemological discourse is of great interest for students' understanding, for several reasons. The new way of seeing the reality to which students are being introduced and the learning demands it represents (Leach \& Scott, 2002) generally means a quite large change in their way of thinking. We are not implying that learning science represents the same kind of challenge as a scientific revolution; but we might assume that the demands imposed upon the 
students would be lowered if we made clear to them the change that the new way of thinking represents.

We cannot take into consideration all aspects of the real world when elaborating a scientific model; it is important for the students to realise this from the start. This distinction also helps students to become more and more autonomous as they get used to referring to it in the daily classrooms activities.

We also consider it necessary to make explicit the distinction between theories and models, by indicating the role of the theory in the elaboration of models.

In the remainder if this article, following Tiberghien (1994), by 'world of objects and events' we mean any element of knowledge which refers to the material world. By 'world of theories and models' we mean the whole set of statements, more or less structured and explicit, which are available for understanding a wide range of situations, and constitute explanatory systems. These notions can be applied both in the context of everyday life and in the context of science instruction. Of course, the nature of theory in one case and in the other is deeply different (see the discussion in Vosniadou, 1994: 47), but in both cases the word 'theory' is justified by an explicative power and a general validity.

We consider that it is necessary, during instruction, to introduce a clear distinction between the world of objects and events and the world of models and theories, and to acknowledge that the relations between these two worlds are not the same when we speak from an everyday as opposed to a scientific point of view. In this way, we help students to make sense of a 'world' that sometimes is at odd with their commonsense view on the matter being considered.

\section{Meaning making in science classroom}

\section{The problem of representations: semiotic registers}

Another related, but distinct, point is the necessity to take into account the issue of representations in analysing classroom discourse and practice; it stems from the consideration 
that science discourse is multimodal (Lemke, 2002). Works on the area of multimodality tends to be 'oriented to the detailed description of speech, writing, gesture and action, and the visual, and the description of their interaction in communicational ensembles and their use' (Kress et al., 2001) in science classrooms. Duval (1995: 21) specifies some kind of semiotic systems, which he calls semiotic registers, and which have three cognitive features: they can constitute a perceptible trace of something which can be identified as a representation; they are provided with rules allowing to transform some representations into others, so that the new ones carry additional knowledge compared with the former ones; they can be converted in representations into another register, so that this conversion allows to express new meanings about what is represented. The main semiotic registers used in science classes are natural language, mathematical symbolism, graphs, and diagrams.

\section{Characterizing dialogic and authoritative discourse}

In this paper we shall use the analytical framework developed by Mortimer \& Scott (2003) to characterize classroom discourse. The framework is based on five linked aspects, which focus on the role of the teacher, and are grouped in terms of Teaching Focus, Approach and Action: teaching purposes, content, communicative approach, teacher interventions and patterns of interactions (figure 1). For the purposes of the analysis presented here we shall focus our attention on the Communicative Approach.

Insert figure 1 about here

The concept of Communicative Approach provides a perspective on how the teacher works with students to develop ideas in the classroom. According to the authors, when a teacher works with students to develop ideas and understanding in the classroom, their approach can be characterized along a dimension, which extends between two extreme positions: either the 
teacher hears what the student has to say from the student's point of view, or the teacher hears what the student has to say only from the school science point of view.

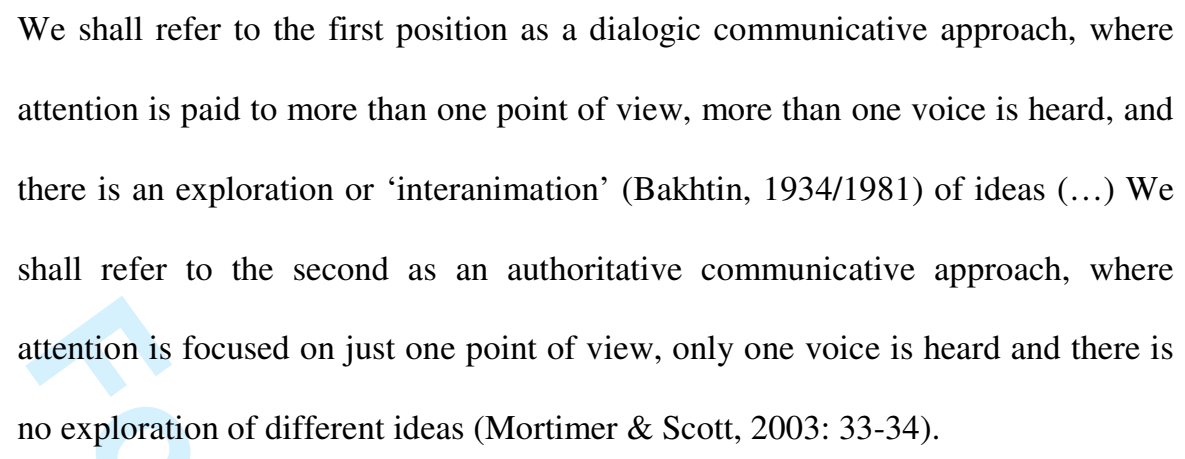

According to Mortimer \& Scott (2003) an important feature of the distinction between dialogic and authoritative approaches is that a sequence of talk can be dialogic or authoritative in nature, independent of whether it is uttered individually or between people. What makes talk functionally dialogic is the fact that different ideas are acknowledged, rather than whether it is produced by a group of people or by a single individual. This point leads the authors to present the second dimension to consider when thinking about the Communicative Approach: that the talk can be interactive in the sense of involving the participation of more than one person in the discourse, or non-interactive in the sense of involving the participation of only one person.

As in this article the four episodes to be analysed are interactive, we shall restrain our analysis to the dialogic/authoritative dimension. Although these aspects were developed in relation to the teacher's role and actions, they can also be used to characterise student-student interactions in the classroom.

In analysing the communicative approach we must be aware of the reserve made by Scott, Mortimer and Aguiar (2006: 627) that "we cannot classify a single utterance as being dialogic or authoritative. This is a criterion that applies to a number of utterances that constitute an episode of meaning making." This is a consequence of the Bakhtinian principle that any utterance is a link in the chain of speech communication. 
An important point in identifying the communicative approaches is that their emergence in science classroom is closely linked to the use of different social languages (at least everyday and school science social languages) and speech genres in the instructional practices, a point we shall develop on the next topic.

\section{Speech genres, social languages and secondarisation attitude}

Bakhtin assumes that language is never unitary. 'It is unitary only as an abstract grammatical system of normative forms, taken in isolation from concrete, ideological conceptualisations that fill it, and in isolation from the uninterrupted process of historical becoming that is a characteristic of all living languages' (Bakhtin, 1934/1981, p. 288). To model this heterogeneity, Bakhtin proposes two forms of stratification of language: the notions of social language and of speech genre.

A social language is 'a discourse peculiar to a specific stratum of society (professional, age group, etc.) within a given social system at a given time' (Bakhtin, 1934/1981, p. 430). All social languages are 'specific points of view on the world, forms for conceptualising the worlds in words, specific world views, each characterized by its own objects, meanings and values (...) As such they encounter one another and co-exist in the consciousness of real people' (Bakhtin, 1934/1981, p. 291-292). In Bakhtin's view, a speaker always produces an utterance using a specific social language that shapes what he/she can say.

On the other hand, 'a speech genre is not a form of language, but a typical form of utterance; as such the genre also includes a certain typical kind of expression that inheres in it $(\ldots)$ Genres correspond to typical situations of speech communication, typical themes, and, consequently, also to particular contacts between the meanings of words and the actual concrete reality under certain typical circumstances' (Bakhtin, 1953/1986, p. 87).

Thus, whilst a social language is related to a specific point of view determined by a social or professional position, the speech genre is related to the social and institutional place where the 
discourse is produced. So, in orchestrating the ways talk is produced in classrooms, teachers will resort to at least two different social languages - everyday life and school science social languages - and to a variety of speech genres, which includes narratives, descriptions, explanations, different patterns of interaction, etc.

Bakhtin also distinguishes 'primary genres' ('simple' ones), which 'have taken form in unmediated speech communication ... have an immediate relation to actual reality and to the real utterances of the others' (op.cit., 62); and 'second genres' ('complex' ones), 'novels, drama, all kinds of scientific research, major genres of commentary... [which] arise in more complex and comparatively highly developed and organized cultural communication (primarily written) that is artistic, scientific, socio-political, and so on' (op.cit., 62). Bautier and Goigoux (2004) have extended these categories. They define the 'secondarisation attitude' as a response from the student to the demand of 'constituting the world of academic objects as a world of objects to be investigated, on which s/he can (and must) perform specific thought activities and work'. In adopting this attitude the student become able to 'establish a circulation of knowledge and activities from one moment and from one academic object to others', what can result in the understanding that 'a problem to solve looks like others which have already been solved' (Bautier \& Goigoux, 2004: 91, our translation). They claim that most of the students focus 'on the ordinary, everyday meaning of tasks, objects or words [which] seems to prevent them constructing the second academic dimension of these objects' (ibid.).

\section{Comments on the links between these theoretical elements}

We have explained four theoretical elements: a view of modelling processes in science and of their explanation in science instruction; the interplay between semiotic registers; a characterisation of communicative approaches in classroom; social languages and speech genres. This section is devoted to the articulation between these elements. 
The common core of these elements is the working hypothesis that understanding comes from relationships between several descriptions or points of views, and consequently that the process of understanding can be facilitated by making these relationships explicit.

In general terms, Mortimer and Scott assume that dialogic discourse is open to different perspectives. Although the authors have used the dialogic-authoritative dimension to characterize whether or not the teacher attends to the students' points of view as well as to the school science view, we use this dimension to consider the dialogic potential of modelling activities: situations in which the teacher pays attention to more than one point of view, even when these different points of view were not taken from the students suggestions or ideas. In talking about a material situation in terms of both the world of objects and events and the world of theories and models a teacher offers an opportunity to the students to see things from different angles, which has a potential to bring different points of view to the understanding process. As Voloshinov (1929/1973: 102) says, any deep understanding, or meaning making, is dialogic in nature because one lays down a set of one's own answering words for each word of the utterance one is in process of understanding. More a teacher makes different points of view available in the classroom, higher is the possibility for the students to lay down different answering words, each one related to a different point of view. In this way, explicit modelling process has a potential to increase dialogicality and understanding in classrooms.

Representational issues (the distinction between several semiotic registers and the conversion from one register to another) must not be confused with epistemological issues (the distinction between the two worlds): although perceptible, a schema on a textbook is not an object, and an animation on a computer screen is not an event. Nevertheless, these representations are connected to the two worlds because they are ways to represent, to work on and to make public and subject to discussion, some elements of knowledge belonging either to the world of objects and events or to the world of theories and models. Our main 
concern when speaking about semiotic register in this paper is related to the potential of establishing relationships between different points of view that the changes between semiotic registers bring about.

In considering the potential that modelling and the use of different semiotic registers has to favour the emergence of dialogic discourse we offer a way of expanding the dialogicauthoritative dimension of classroom discourse proposed by Mortimer and Scott (2003). Nevertheless, we are not suggesting that dialogic discourse emerges every time someone makes explicit links between the world of theories and models and the world of objects and events. For example, if the teacher establishes these links from the point of view of school science the discourse probably will be located in the authoritative dimension. We suggest that, when seeing things from different modelling points of view or using different semiotic registers to represent a phenomenon, students enlarge their view on the phenomenon, which potentially increases the number of answering words the students lay down in trying to understand the situation.

For the analysis of classroom discourse alongside the dialogic-authoritative dimension we are interested in this paper, the distinction between primary and secondary speech genres and the emergence of secondarisation attitudes are fundamental aspects to pay attention in the discourse. The use of primary genres is closely linked to the use of the social language of everyday life and the use of secondary genre will emerge as a consequence of the "translations" between the semiotic register of natural language and other more specialized semiotic registers - diagrams, graphics and equations, used in science. These translations also have the potential to favour the emergence of different points of view, which characterize dialogic discourse. 


\section{Research questions}

These theoretical considerations allow putting forward the following general hypothesis, which could be a part of a global research program: dialogic discourse may help students to establish the relationship between the world of objects and events and the world of theories and models, which is a central feature of understanding modelling processes. In this perspective, it is relevant to investigate if the teacher presents different points of view, which is at the core of dialogic discourse: does s/he talk about the two worlds from the physics point of view on the one hand and from the everyday-life point of view in the other hand? In this articulation of two points of view, does s/he use and relate different social languages, different speech genres and different semiotic registers?

This hypothesis can be considered here as a working one, which cannot be (dis)confirmed by the data of a specific paper, but emerges as a consequence of articulating the two theoretical perspectives - modelling and dialogism.

In this paper, we begin to address these questions in a case study, by a qualitative analysis of classroom discourse, involving several episodes in different sessions of a complete teaching sequence. Thus, the data come from a single class, with a single teacher. By the qualitative analysis which follows, we do not pretend anything more than performing a first test of the fruitfulness of combining these two frameworks - modelling and communicative approach for classroom discourse analysis.

In this context, we are interested in answering the following much more specific questions:

- How did the teacher manage the dialogicity and the modelling processes in the classroom discourse?

- What were the difficulties he encountered in linking the various points of view, relatively to modelling processes or to semiotic registers?

- What were the consequences of these difficulties for students' understanding? 


\section{Content and features of the teaching sequence, methods and samples}

For many years, the previously exposed considerations on modelling have informed the way teaching sequences have been designed in a collaborative work with teachers (Tiberghien, 2000; Gaidioz, Vince \& Tiberghien 2004). The teaching sequence in Optics (grade 11) which will be discussed in this article has been elaborated in the same way. It is grounded on the following learning hypotheses:

- In class activities, and particularly in practical sessions, students have to establish links between the theories/models they are supposed to learn and the experiments they are asked to carry out.

- The main difficulty they face to understand and learn science is to understand the world of theories and models and to establish the links between this world and the world of objects and events. It other words, a deep understanding of concepts and of the relations between concepts depends not only on the learning of models and theories but also on the construction by students of meaningful links between the two worlds.

- Students are likely to use their own previous 'theory' (normally implicit and constructed from everyday experience or previous teaching) for this purpose instead of the science theory they do not know yet or do not understand completely. For example, such a naïve theory can incorporate statements like "in order to set an object into motion I need to push or pull it" which, although wrong from a scientific point of view, may be considered by students as explicative in a given situation.

In line with the official curriculum, the teaching sequence on Optics, which has been elaborated, included the following topics: the rectilinear propagation of light, the image formation through a converging lens (real and virtual image), and the image through a plane 
mirror. The whole teaching sequence is divided into fifteen activities. An activity is 'a relatively self-contained, goal-oriented unit of activity, which is recognized as such by the participants' (Wells, 1999: 172) and includes a coherent set of tasks students should do (experiments, drawings, exercises, answers to questions) and of actions and verbalizations from the teacher.

Some choices have been done about the use of some words in the texts given to students coherently with our concern about modelling processes. The word 'ray' was reserved for an element of the model, like the word 'beam' which indicates an infinite set of rays. The phenomena these words model are referred to by the expression 'light flux'. This choice can be considered as a consequence of the hypothesis about the necessity of making explicit the modelling processes.

Nevertheless we are conscious that some words are unavoidably bivalent, and will be used by students (and often also by teachers) to refer to the world of objects and events or to the world of theory and models indifferently. This bivalence probably also helps students to understand the relationship between the two worlds, because it may initiate the link between them.

The teaching sequence alternated lessons for the whole class (9 hours) and experimental sessions (three of 2 hours each) with half of the class. Every episode analyzed here was part of an experimental session. In the experimental sessions, the students worked in pairs. The whole sequence was video recorded using two cameras. One of the cameras was placed on the back of the room with a wide angle centred on the teacher, and the other focused on a pair of male students, Mat and Ale, in a close-up. The video recordings were transcribed; the transcripts include all the verbal productions that were understandable and a description of the gestures that were considered as meaningful by the researchers. In doing the analysis we resorted both to the videos and to the transcripts. 
A rather important point is that the observed teacher had participated in elaborating the teaching sequence; he was consequently aware of the epistemological issues underlining the design of the various activities, especially the positive effects expected from a clear separation between the two worlds. But no indication had been given about communicative approaches, and he himself chose his patterns of talk. To this regard, he was a "normal" teacher. The present analysis is then a "natural" one regarding the communicative approaches but not regarding the epistemological aspects.

\section{Results and Analysis}

Normally, the communicative approach in this curricular unit is almost all the time interactive. The teacher tries to encourage students to express their opinions and listens to what they have to say. In order to show dialogic potential of the modelling process and some difficulties linked to the maintenance of dialogic communicative approach and its relationships with the modelling processes, we present below the analysis of four episodes of the sequence. These four episodes took place in the activities 1, 2, 6 and 14 respectively (among 15).

A categorisation of the whole transcripts of the teaching sequence had been achieved for another work by the authors, as regards to the communicative approach. The relevant episodes for our present purpose were selected from the transcripts and checked for the categories of communicative approach, and completed for the categorisation of modelling processes and semiotic registers.

\section{Episode 1: explanation of the text of the model}

In the first activity, an introductory one, the students and the teacher read a text called 'text of the model', which gave a number of theoretical statements to be used by students during the 
Insert figure 2 about here

Insert table 1 about here

\footnotetext{
${ }^{1}$ In the transcripts of the activities to be analyzed here, we numbered the turns of talk from the beginning of the activity. In the second column we indicated the speaker ( $\mathrm{T}$ for the teacher, $\mathrm{Nl}$ for a student we could not identify, $\mathrm{Cl}$ for the whole class); in the third we indicated the transcription of the talk produced by the participants, and if necessary, the person addressed in the talk (if no indication is given, the addressee is the whole class); in the last column we gave indication of non verbal actions. In order to make the transcription simple, we adopted a simplified code for transcribing the oral language: we kept the dot (.), the question mark (?) and the exclamation mark (!), without the usual parentheses, to indicate a stress in the intonation, or a shift in the tone indicating a question or an exclamation (these notations are thus inferences of researchers); a slash (/)
} 
The teacher begun this episode by making explicit the same sort of relationship for the word 'isotropic' (he considered the word 'homogeneous' as known by students). On turn 84 he translated the word isotropic: "isotropic it means that if I make the experiment changing the direction / of the LASER this will not change anything at all in this experiment / the light behaves in the same way regardless of the direction of light propagation / this is not the case of all the mediums". At the same time he moved his hand all over to change the direction of the laser beam. In his talk he begun with expressions from everyday language as 'changing the direction' and 'this will not change anything at all in this experiment' and ended with an expression that is closer to the words of the model: 'the light behaves in the same way regardless of the direction of light propagation'. Through this set of language and gesture he assured that each word of the model corresponds to a real object or event and to their expression in the words of everyday language.

It is worth noting that this "translation" involves the same sort of phenomenon we described as secondarisation. The expressions in everyday language have a direct and unmediated relationship with the objects and events they refer to, which characterize the primary speech genres (Bakhtin, 1986). In the language of school physics this relationship is mediated by the theoretical conceptual system and its particular expressions and this characterizes the secondary speech genres. Thus, at the same time that he puts the two worlds in relation he adopts explicitly a secondarisation attitude, by making clear the relationship between the primary genre used to name objects and events of everyday life and the secondary genre of school physics and of everyday life. In doing so he also presents two points of view, which characterizes dialogic discourse: the point of view of geometrical optics and how it relates to the point of view of everyday life, represented here by its natural objects and its expression in everyday language.

indicates a small pause; when the pauses lasted longer, an approximate duration was indicated between parentheses (for example (2s)); brackets ([ ]) indicate simultaneous talk. 
As the teacher was able to demonstrate the relationship between these two worlds and two points of view we suggest that the modelling activity, in this case, has a potential to bring dialogic discourse into being. Up to turn 84 , the teacher used this potential very well. Nevertheless, the teacher did not make the same sort of relationship between the worlds of theories and models and the worlds of objects and events when he talked about the light ray. In turn 85 a student read the statement of the model that introduced the concept of light rays: 'under the conditions of geometrical optics / the light is modelled by the light rays'. In the following turns, instead of referring to the world of objects and events as he had done with all the others features of the model, the teacher made sure that the students already knew the words (turn 86) and focused on how to represent the light rays in the same semiotic register than for the experiment with the laser beam (turn 88). For the rectilinear propagation of light the teacher simply repeated the words of the models (turn 92), stressing the condition that the medium should be homogeneous and isotropic if this principle was to be observed. Again, no reference was made to the world of objects and events. Right after, a student read the counter intuitive feature of the model that a light ray has a null width (turn 93). Again the teacher made no reference to the world of objects and events but explained what it meant to represent a ray with null width in a schema.

Remarkably, when he turned his attention to the colour as a perception, which the model associated with the wave length (turns 101-102), the teacher returned to the link between the two worlds; when he came back to the representation of a ray (turns 103-105), the teacher went back to the representation only.

From these observations we can infer that the teacher did not used the dialogic potential of the differentiation between the worlds of model and theories and the worlds of objects and events when talking about the light rays as he did for the other features of the model. The text of the model itself seemed, to a certain extent, to lead the teacher to do so. Referring to appendix 1, 
we can see that the modelling of light fluxes as sets of rays, although present (lines 3 and 5), is quite allusive. The issue of the shape and dimension of light areas which can be modelled by rays and beams is not explicitly considered. A large amount of explanations remains implicit and left as a work to be done by teachers, which can account for the problems discussed in this paper.

What were the consequences of this lack of differentiation between the two worlds to the ways the light rays were referred to throughout the sequence? For answering this question we searched the words 'ray' and 'beam' (in French, 'rayon' and 'faisceau') throughout the transcriptions to get a sense in the ways these words reappeared in the sequence. The word 'ray' reappeared in a far larger number than the word 'beam'. Generally speaking, the lack of explicit differentiation between the worlds of model and theories and the worlds of objects and events persisted throughout the sequence when the teacher talked, interactively or noninteractively, of light rays. In what follows we are going to present some episodes which will exemplify this issue.

\section{Episode 2: what is the status of a ray?}

The second episode we are going to analyze (see transcription table 2) was taken from an experimental activity aimed at providing evidence of, and discussing, the rectilinear propagation of light. The episode happened in the end of the activity, when the teacher asked the students to decide which lines in the 'text of the model' were at stake in the activity. The teacher was talking to the whole class, and suddenly Ale interrupted him (turn 275), making a comment related to the topic. The teacher engaged in a discussion with Ale, which could be heard by the whole class.

Insert table 2 about here 
The part of interest in this second episode comprises turns 275 to 289 and it shows an interaction between the teacher and Ale. Ale initiated the talk sequence expressing the idea that a light ray belongs to the world of objects and events, through his statement in turn 275 that 'but you cannot isolate [a ray]'. The teacher initially accepted the invitation to dialogue and answered from the point of view of the theoretical model: 'no, but you can represent it'. Nevertheless, in turn 280 the teacher introduced an ambiguity in his discourse by referring to the ray using the deictic 'one' and the same expression used by Ale ('you can isolate'). It is quite natural for a teacher to take the words his student offers in a verbal interaction and the word 'ray' carries this unavoidable ambiguity of belonging to both the worlds of objects and events and of theories and models. Nevertheless, by acting that way, the teacher unconsciously contributed to blur the difference between his 'ray' as a model and the student's 'ray' as an object, as he oscillated between the words 'represent' and 'isolate' to refer to a ray. From this moment to the closure of the episode there was a tension between dialogic and authoritative discourse as the teacher, at the same time that he took into account Ale's objection, failed to explicitly differentiate between the two points of view. As a consequence, he did not help Ale to realize that the isolated ray is an entity in a theoretical model, not an object. This is confirmed by the final intervention from Ale, when he implicitly asserted that one day one infinitely small pencil of light will be isolated, as he agreed only 'nowadays' with the teacher still ambiguous statement that 'a ray can be represented, so it can be isolated'.

This episode illustrates the difficulties the teacher faced to make explicit the differentiation between the world of objects and events from the world of theories and models, when talking about light rays. He failed to establish the relationships between the two worlds in the same way as he had failed in the first episode, although in this second episode the point of view which remained implicit in the first episode - what is a ray in the world of objects and events 
- was made explicit by Ale, who treated the ray as an object and not as an element of the model. This means that the dialogical potential of this episode was still higher, as the question that remained implicit in the first episode (what is a light ray in the world of objects and events?) was answered by Ale, but from a point of view that was not the scientific one. Nevertheless, the answer to this question from the point of view of the physics remained implicit. This episode also illustrates how a student trying to speak from the point of view of school science can contribute to the dialogic differentiation between these two worlds. But this also depends on the ability of the teacher to perceive the dialogic potential of these kinds of initiative from the students.

\section{Episode 3: the masked lens}

The third episode (see transcription in table 3) came from an activity in which the students had to predict what would happen if they put a mask in front of a converging lens giving a real image from a real object (the light source in figure 3). Would the image be partly hidden? As expected, in line with the literature in this domain, most of the students answered that part of the image would disappear. This answer was a consequence of the 'travelling image' conception, and was in contradiction with the scientific point of view of 'mapping point to point' between the object and the image (Galili, 1996). After having written their prediction, students did the experiment, and tried to explain why their prediction was different from what they observed.

The episode took place at the end of the activity, after the students had done the experiment.

Insert figure 3 about here

Insert table 3 about here 
Only cases A (world of objects and events, described in natural language) and D (schematic register for representation of the world of theories and models) were used in this episode: case A corresponds to the explanation given by the teacher by using the word 'light' (255); case D corresponds to the diagram the students have done, and to the diagram projected by the teacher.

We can observe that the teacher did not fully interpret his schema in terms of natural theoretical language (case C). He never said things like 'a mask on the lens stops some rays, but others rays in the beam coming from each point of the object can pass through the part of the lens which is not masked, so these rays can gather in a point, which is the image point, so the observed image is complete'. His interpretation was given only in terms of perceptible 
events (that the image is less luminous), case A. Case B (schematic register representing the world of objects and events) was excluded by the instructions, as the students were not asked to draw a schema of the real objects. We can consider that the teacher did a 'short-circuit', passing directly from $\mathrm{D}$ to $\mathrm{A}$, without giving a theoretical explanation in natural language. This kind of 'short-circuit' is quite common in science classrooms and has important consequences for the development of secondarisation attitudes by students. Although theoretical explanation in natural language already characterizes the use of a secondary genre, in which the relationships between the words and the objects are not direct but mediated by a conceptual system, it seems to be easier for students to move from primary to secondary genres if both genres are firstly expressed in a less artificial semiotic register - that of natural language. Translating the world of familiar objects and events - in this case the 'image' - in diagrams seems to involve two sorts of transitions, each one offering some kind of difficulty: the transition between primary and secondary genres, both expressed in the same semiotic register of natural language; and the transition between the semiotic register of natural language and that of the diagrams. The absence of any of these steps in the path between the world of objects and events and the world of theories and models seems to make more difficult to handle the situation. The teacher thus missed the dialogic potential of the modelling activity for bringing two semiotic registers in contact, here the part of the concept of image expressed in the natural language and the part expressed in the diagrammatic register.

It is also interesting to remark how the word 'image' was used in this exchange. This word is typically a 'bridge' between two modelling levels and between primary and secondary speech genres: in the world of objects and events, it indicates what students can perceive on the screen (as in turns 251, last occurrence, and 262, two occurrences), and in this sense can be used in both primary and secondary genres; in the world of theories and models, it indicates 
Insert figure 4 here

\section{Insert table 5 here}

This episode happened in the last but one activity of the sequence and showed Ale at ease with the task of making diagrams. The episode is very illustrative because of Mat's question at the very beginning (turn 200: 'a beam / what is a ray a ray and a beam') which means 'what is the difference between a ray and a beam?' The question allowed for both Ale and the teacher to express their partly coincident definitions. The meaning Ale expressed associated to 
'ray' was just restricted to the schematic register: 'a ray is exactly this that you have represented' (turn 201). To explain that a beam 'is the set of two rays' (turn 203) Ale asked Mat to represent a second ray. In turn 211 the teacher made explicit his definition ('a beam of light is a set of rays / these are all the rays coming from the point $\mathrm{A}$ in this case inside these two rays'). The understanding of the notion of 'beam' by Ale seems restricted to the schematic register, and to the extreme rays of a beam.

This episode confirmed that the schematic register had the priority in referring to rays and beams. The status of such entities was never talked about in the register of natural language after the 'incident' described in episode 2. Although Ale demonstrated that he had mastered how to operate with the concept of ray and beam in the schematic register, which allowed him to do all the diagrams in the activities on this sequence, it is not possible to know if he had changed the status he had attributed to the ray in episode 2: something belonging to the world of objects and events that 'we cannot isolate' 'nowadays'. In episode 4 the discourse was clearly authoritative as the students and the teacher were talking from the same school science point of view, yet, from a limited angle inside this conceptual horizon, the one of the semiotic representation of entities.

\section{Discussion}

The analysis of the four episodes raises some questions related both to the nature of modelling activities, of the use of various semiotic registers, and to their potential to bring dialogic discourse into being in the classroom. The story being told by the four episodes is one of missing this potential, offered by the differentiation between the two worlds. Even when a student (Ale, in the second episode) offered a different point of view, bringing dialogicality into the talk, the teacher failed to get the point. When the teacher did not explore every possibilities of dialogism, some 'short-circuits' were operated: the teacher did not take all the available steps to make the transition between primary and secondary speech genres. It led to 
the situation where the student mastered the operational definitions of rays and beams, but his achievement of secondarisation remained uncertain. School is always in a pressure for time and once more this had as a consequence the emphasis in the operational aspects of science in detriment of the conceptual ones.

Another point to be made relates to the first episode and the nature of modelling it suggests. During this episode, in the flow of discourse in the class, two kinds of words appeared which corresponded to two different mechanisms of modelling. The first one consists of words like source, receptor, medium, which correspond to elements of the experiment (the laser pointer, the screen, the air). These words referred to some objects in the real world, as expressed by the primary genres used in everyday language, with their unmediated link to the objects. These words had also a function in the secondary genres that are being introduced, of modelling these elements in the real experiment. By considering only this kind of words and by establishing a correspondence of each word of the model to an object or event, one could implicitly consider that models always match the reality in a univocal way: each entity in the world of objects and events is modelled by an entity in the model and each entity of the model has a correspondent in the world of objects and events (Tiberghien \& Megalakaki, 1995; Collet 2000). But the entity 'rays' goes beyond this univocal relationship, like many other key terms in science, and thus belongs to a second category of words. Although the idea of a "ray" is suggested by our experience with natural phenomena like 'solar rays', the ray as it is defined into the model does not exist in the word of objects and events, it is imposed upon it by the optical model: it is an idealization from real perceptions. Thus, in this second category of words, the unmediated relationships these words have with the objects in primary speech genres are problematic for their understanding in the context of school science. They begin to exist in science classrooms as part of secondary speech genres, in which the relationship between the words and the objects is always mediated by a conceptual system. The important 
point here is that there are entities that go beyond this univocal and functional relationship between the world of models and theories and the world of objects and events.

When we think about how the status of atoms and molecules changed alongside the history of science, we can infer that science tends to 'create reality' from its models. Atoms and molecules started as clear non consensual entities in a model in the beginning of the XIX century, changed to consensual entities in a model in the beginning of the XX century to end as real entities that can be manipulated in nanotechnology in the beginning of the XXI century. So, it is not a surprise that Ale thought that a single ray might be isolated one day.

The second category of words (ray, image, force, power, current...) can be seen as 'bridging words': they are used both in speech genres of everyday life for referring to elements of the world of objects and events and in the school science speech genres for elements of the world of theories and models, with different but correlated meanings. Consequently they present both advantages as well as risks: the internalisation of their meaning in the school science speech genres can be helped by the correspondences with their meaning in genres of everyday life (it is the idea of founder notions, see Buty et al., 2004: 585); but the distinction between the two different meanings can also be blurred. One of the instructional tasks when using these words is to help students distinguishing when they may use them in one speech genre or in the other.

It is interesting to notice that these views are probably not limited to science learning and understanding, and can be considered from a broader instructional point of view. In our point of view, modelling processes in science teaching and learning could favour secondarisation attitudes: a clear distinction between the worlds of objects and events allows students to consider the theoretical construction of science and the scientific discourse as 'second' realities created by secondary speech genres (as Bakhtin explicitly said), in which the 
relationships between words and objects are not direct but mediated by a conceptual system; if, besides making clear the distinction between the two worlds, the teacher favours the distinction between the points of view of school science and the everyday ones, this attitude can favour a deep dialogic understanding of physical models and theories, as it becomes possible for students to put the primary and second planes, and also the primary and secondary genres in dialogue and to 'lay down a set of their own answering words for each word of the utterance they are in process of understanding' (Voloshinov, 1929/1973: 102).The generalisability, a major property of scientific models, precisely allows students establishing 'a circulation of knowledge and activities from one moment and from one academic object to others' (Bautier \& Goigoux, cf. supra, our translation), in the relevant area.

\section{Conclusions and implications}

Let us recall the research questions we have proposed at the beginning of the paper:

- How did the teacher manage the dialogicity and the modelling processes in the classroom discourse?

- What were the difficulties he encountered in linking the various points of view, relatively to modelling processes or to semiotic registers?

- What were the consequences of these difficulties for students' understanding?

Throughout the four episodes we have highlighted a complex interplay between success and failure in the use of the dialogic potential of modelling process, or of semiotic registers. The observed teacher, an experienced one, has for habit to give a large space for students' expression and points of view; in this sense, he has acquired strong enough bases for instituting dialogicity in his classes. From his participation to the elaboration of researchbased teaching sequences, he feels a strong concern for modelling processes and for the clarification of these processes for students. Nevertheless, the lack of theoretical tools or 
guidelines regarding the communicative approaches, comparable to those he masters for modelling processes, sometimes lead him to miss some key steps:

- The distinction (episode 1) between the ray, seen as an object by the everyday language, and the ray, seen as an element of a theoretical model by physics language; this might be the cause of the problems (episode 2) the observed student had in understanding the status of a ray, and his confusion between two models of light; a second consequence was that the teacher suddenly shifted from dialogic to authoritative approach.

- The translation between semiotic registers (episode 3), which was incomplete; we found an echo in the behaviour of students about rays and beams, only handled as drawing elements (episode 4).

The analysis reported here confirms previous results (Mortimer \& Scott, 2003) on the difficulties of reaching a suitable balance between dialogic and authoritative discourse in science classroom. At the same time it adds a new dimension to the problem, in taking into account the difficult task of establishing meaningful relationships between the world of objects and events and the world of theories and models; the teacher's capacity to sustain dialogic discourse appears as a crucial point. A particularly important aspect is the necessity to deal dialogically with words or expressions (rays, beams) which science inherited from everyday language, in order to help students in the process of secondarisation. That teachers explicitly refer to both everyday and scientific points of view in these matters seems, in a dialogic communicative approach, to be crucial for allowing students to differentiate between the two points of view and to recognize that these words can be expressed and thought about in more than one semiotic register.

These results give some insights on possible direct implications for teaching practice and teacher training. The analysis of episodes in which dialogic discourse is prematurely aborted, when it still has a potential for the purpose of teaching modelling activities, can help teachers 
to reflect on their practice in order to reach an appropriate balance between dialogic and authoritative discourse in classrooms.

By this analysis, we claim we have contributed to the development of the two theoretical frames, modelling processes and communicative approaches, in line with the previous trajectory of these ideas.

\section{References}

Bakhtin, M. M. (1934/1981). The dialogic imagination. M. Holquist (ed.), C. Emerson \& M. Holquist (trans.), Austin, University of Texas Press.

Bakhtin, M. M. (1986). Speech Genres \& Other Late Essays. Ed. by C. Emerson \& M. Holquist(eds.). Austin, University of Texas Press.

Bautier, E. (2004). Formes et activités scolaires, secondarisation, reconfiguration, différenciation sociale. In Hommage à $V$. Isambert-Jamati. Presses Universitaires de Provence.

Bautier, E., \& Goigoux, R. (2004). Difficultés d'apprentissage, processus de secondarisation et pratiques enseignantes : une hypothèse relationnelle. Revue Française de Pédagogie, 148, 89-100.

Besson, H., \& Viennot, L. (2004). Using models at the mesoscopic scale in teaching physics: two experimental interventions in solid friction and fluid statistics. International Journal of Science Education, 26(9): 1083-1110.

Buty, C., Tiberghien, A., \& Le Maréchal, J-F. (2004). Learning hypotheses and an associated tool to design and to analyse teaching-learning sequences. International Journal of Science Education, 26, 579-604.

Candela, A. (1999). Ciencia en la aula: los alumnos entre la argumentacion y el consenso. Ciudad de Mexico, Paidos Educador.

Collet, G. (2000). Langage et modélisation scientifique. Paris, CNRS éditions. 
Crawford, B. A., \& Cullin, M. J. (2004). Supporting prospective teachers' conceptions of modelling in science. International Journal of Science Education, 26(11): 1379-1402.

Devi, R., Tiberghien, A., Baker, M., \& Brna, P. (1996). Modelling students' construction of energy models in physics. Instructional Science, $\mathrm{n}^{\circ} 24$, pp. 259-293.

Duval, R. (1995). Sémiosis et pensée humaine. Berne, Peter Lang.

Gaidioz, P., Vince, J., \& Tiberghien, A. (2004). Aider l'élève à comprendre le fonctionnement de la physique et son articulation avec la vie quotidienne. Bulletin de l'Union des Professeurs de Physique et de Chimie, 98 (866), 1029-1042.

Galili, I. (1996). Students' conceptual change in geometrical optics. International Journal of Science Education, 18, 847-868.

Gilbert, J., \& Boulter, C. (1998). Learning science through models and modelling. In B. Frazer and K. Tobin (eds.), The International Handbook of Science Education. New York, Kluwer, 53-66.

Gobert, J. D., \& Buckley, B. C. (2000). Special issue: introduction to model-based teaching and learning in science education. International Journal of Science Education, 22(9): 891-894.

Grosslight, L., Unger, C., Jay, E., \& Smith, C. (1991). Understanding models and their use in science: conceptions of middle and high school students and experts. Journal of Research in Science Teaching, 28, 799-822.

Justi, R. S., \& Gilbert, J.K. (2002). Modelling, teachers' view on the nature of modelling, and implications for the education of modellers. International Journal of Science Education, 24(4): 369-388.

Kelly, G. J., \& Brown, C. (2003). Communicative demands of learning science through technological design: Third grade students' construction of solar energy devices. Linguistics and Education, 13, 483-532. 
Kress, G., Jewitt, C., Ogborn, J. \& Tsatsarelis, C. (2001). Multimodal teaching and learning. London, Continuum.

Kuhn, T.S. (1970). The structure of scientific revolutions. Chicago, The University of Chicago Press.

Leach, J., \& Scott, P. (2002). Designing and evaluating science teaching sequences: an approach drawing upon the concept of learning demand and a social constructivist perspective on learning. Studies in Science Education, 38, 115-142.

Lemke, J.L. (1990). Talking Science. Norwood, Ablex.

Mortimer, E.F. (1998). Multivoicedness and univocality in classroom discourse: an example from theory of matter. International Journal of Science Education, 20(1): 67-82.

Mortimer, E.F., \& Scott, P.H. (2003). Meaning making in secondary science classrooms. Maidenhead: Open University Press.

Ogborn, J., Kress, G., Martins, I., \& McGillicuddy, K. (1996). Explaining science in the classroom. Buckingham, Open University Press.

Roychoudhury, A., \& Roth, W.-M. (1996). Interactions in an open-inquiry physics laboratory. International Journal of Science Education, 18(4): 423-445.

Scott, P.H. (1998). Teacher talk and meaning making in science classrooms: A Vygotskian analysis and review. Studies in Science Education, 32: 45-80.

Sutton, C. (1992). Words, science and learning. Buckingham, Open University Press.

Tiberghien, A. (1994). Modelling as a basis for analyzing teaching-learning situations. Learning and instruction, 4(1): 71-87.

Tiberghien, A. (2000). Designing teaching situations in the secondary school. In R. Millar, J. Leach \& J. Osborne (Eds.), Improving science education: The contribution of research Buckingham, Open University Press, 27-47. 
Tiberghien, A., \& Megalakaki, O. (1995). Characterisation of a modelling activity for a first qualitative approach to the concept of energy. European journal of psychology of education, 10(4), 369-383.

Treagust, D. F., Chittleborough, G., \& Mamiala, T. L. (2002). Students' understanding of the role of scientific models in learning science. International Journal of Science Education, 24(4): 357-368.

Voloshinov, V.N. (1929/1973). Marxism and the Philosophy of Language. Cambridge, M.A., Harvard University Press.

Vosniadou S. (1994). Capturing and modeling the process of conceptual change. Learning and Instruction, 4(1), 45-70.

Wells, G. (1999). Putting a Tool to Different Uses: A Reevaluation of the IRF Sequence. In Wells, G. Dialogic Inquiry: Towards a Sociocultural Practice and Theory of Education. Cambridge, Cambridge University Press.

Ziman J. (2001). Real Science: What it is, and what it means. Cambridge, Cambridge University Press. 


\section{Appendix 1: extract of the 'text of the model'}

The following text was given to the students at the very beginning of the sequence.

1. Light propagates from a light source to a receptor through a transparent medium. It conveys energy from the source to the receptor.

2. The word 'medium' indicates the matter which is passed through by light. When its optical properties are the same everywhere, we say that the medium is homogenous. When its properties are the same whatever the direction of the light may be, we say that the medium is isotropic.

3. In the conditions of geometrical optics, light is modelled by light rays.

4. In an homogenous and isotropic medium, a light ray has:

a. A straight and unique direction ('principle of the rectilinear propagation of light')

b. No width

c. A given wave length or a given range of wave lengths, linked to the colour sensation

It is represented by a line, a half-line or a segment.

5. A light flux is modelled by a light beam, continuous set of rays (....)

6. The human eye is an important receptor (...) Our brain is trained to interpret light sensations according to the principle of the rectilinear propagation of light. 
Figure 1: Mortimer and Scott (2003) analytical framework

\begin{tabular}{|l|lc|}
\hline \multicolumn{2}{|l|}{} & Aspect of Analysis \\
\hline i. Focus & 1. Teaching Purposes & 2. Content \\
\hline \multicolumn{2}{|l|}{} \\
\hline ii. Approach & \multicolumn{1}{|c|}{ 3. Communicative approach } \\
\hline \multicolumn{1}{|l}{} \\
\hline iii. Action & 4. Teacher interventions & 5. Patterns of Interaction \\
\hline
\end{tabular}


Figure 2: diagram on the blackboard during episode 1

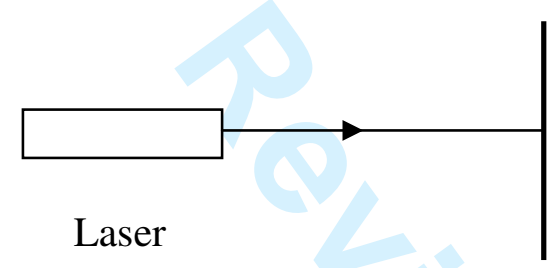


Figure 3: Diagram of the experiment in episode 3

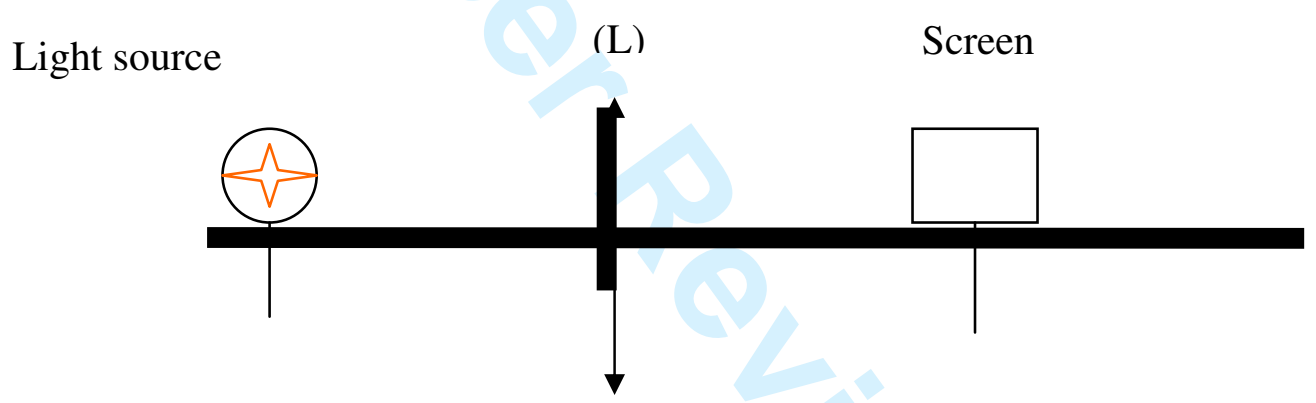

Lens with a mask 
Figure 4: expected students' drawings in the experiment of episode 4 
Table 1: transcription of episode 1, introduction of the double-faced word "ray" 
$79 \mathrm{Nl}$ The word medium designates the matter which is

$\mathrm{Nl}$ reads the text of crossed by the light / when its optical properties are the model the same all over / we say that the medium is homogeneous

$80 \mathrm{~T}$ Homogeneous that is a word you know. Afterwards?

$81 \mathrm{Nl}$ When its optical properties are identical with respect to the direction of light propagation / we say that the medium is isotropic

$82 \mathrm{~T}$ Well do you know this word / isotropic?

$83 \mathrm{Nl}((\mathrm{T}))$ (inaudible)

$84 \mathrm{~T}$ Isotropic this means that if I make the experiment $\mathrm{T}$ shows with his changing the direction / of the LASER this will not fingers the change anything at all in this experiment / the light experiment of behaves in the same way regardless the direction of LASER light propagation / this is not the case of all the $\mathrm{T}$ makes a medium / so let's continue

horizontal movement with his hand to show the direction of light propagation

$85 \mathrm{Nl}$ Under the conditions of geometric optics / the light is modelled by the light rays

86 T So. "light rays" these are words that you have already used?

$87 \mathrm{Cl}((\mathrm{T}))$ Yes 

$88 \mathrm{~T}$ Yes at least at grade $10 /$ if we wanted a ray become visible on the diagram where would we put it? Where would we draw it on the diagram you have just drawn?

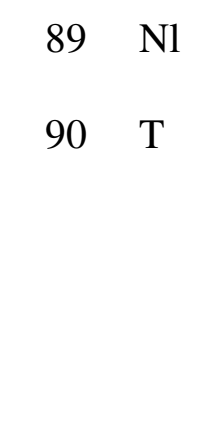

$92 \mathrm{~T}$ This is a principle you all know / light propagates in straight line but pay attention now you should add/ if the medium is homogeneous and isotropic / afterwards

93 Ma ((T)) null width

$94 \mathrm{~T}$ Null width. Did we take this into account in the diagram?

$95 \mathrm{Cl} \quad((\mathrm{T}))$ No

$96 \mathrm{~T}$ No so what could we have done on the diagram to translate the model?

$97 \quad \mathrm{Nl} \quad((\mathrm{T}))$ (inaudible)

$98 \mathrm{~T}$ How can we draw something with null width?

$99 \quad \mathrm{Nl} \quad((\mathrm{T}))$ (inaudible)
T points to the

diagram of the

experiment on the

board

T draws a ray on the

diagram of the

experiment on the

board (see figure 2) 
$100 \mathrm{~T}$ What does this mean? We cannot do anything better

T makes a

than a straight line(.) this translate the fact that the

movement with his

width is null / negligible / null means represented by a

hand to indicates a

line / exactly as you do the straight line in math / or

straight line

the segments / and then

$101 \mathrm{Ma}((\mathrm{T}))$ A certain wave length or a certain range of wave

t length / linked with the colour sensation

$102 \mathrm{~T}$ That's what you have seen in middle school and in

grade 10 you all knew that according to the wave

length the light / gives a sensation of colour which can

change / you know all these things / so let's continue

$103 \mathrm{Ma} \mathrm{((T))} \mathrm{It} \mathrm{is} \mathrm{represented} \mathrm{by} \mathrm{a} \mathrm{straight} \mathrm{line} \mathrm{/} \mathrm{a} \mathrm{semi}$

$\mathrm{t} \quad$ straight line or a segment.

$104 \mathrm{~T}$ Well on the diagram what did we represent it with?

$105 \mathrm{Nl} \quad((\mathrm{T}))$ A segment 
Table 2: transcription of episode 2, can we isolate a 'ray' or represent a 'ray'?

269. T You have instinctively well had the reflex to represent rays and beams/ in which line is it?

277. Ale ((T)) You cannot isolate a ray, right?

278. T ((Ale)) No / but you can represent it

279. Ale ((T)) Yeah

280. T ((Ale)) But in geometric optics you can isolate one / We shall see this later for the moment let's consider we can::
270. Ale ((T)) Ah! it's the rays

271. $\mathrm{Nl}((\mathrm{T}))$ On the five

272. T That's it and the rays on the number three / you have done whether rays or beams

273. Mat ((T)) Three four five

274. T That's it / so you write

275. Ale $((\mathrm{T}))$ [but you cannot isolate]

276. T [We are referring to] /((Ale)) Tell me?
Ale tries to say
something to $\mathrm{T}$ who
directs his attention to
$\operatorname{him}$ 
281. Ale ((T)) (inaudible)

282. T ((Ale)) Where have you seen this?

283. Ale ((T)) No but that's that's not possible

284. T ((Ale)) Why?

285. Ale ((T)) Well I don't know it should have the size of a Ale makes a sign with photon to get something / and still his fingers to show the width of a ray

286. T ((Ale)) Well / this is complicated what you tell me indeed / for the moment in geometric optics / we don't ask this question / and we consider that we can represent a ray / thus isolate a ray / Yes? we do as if / even if nobody has never succeeded I shall say

287. Ale ((T)) Nowadays

Ale turns towards Mat

288. T ((Ale)) It doesn't preclude us to analyse well / by making this hypothesis and by accepting that it is possible

289. Mat ((Ale)) (inaudible)

290. T So you write / for the answer three a / we are

$\mathrm{T}$ begins to draw a referring / particularly to lines three and five (repeated) (2s) to represent the light (repeated) by rays and light beams (6s) and (5s) to line four for rectilinear propagation / as you made rays. (15s) 
Table 3: transcription of episode 3, explanation of the experiment of the masked lens 
$251 \mathrm{~T}$ You should have proposed an answer by now (2s) you have the same scale as yesterday you put an object $\mathrm{AB}$ with 14,5 millimetres instead of 29 at 80 centimetres so 8 centimetres on the scale and the image 57 centimetres (64s). Have you done this diagram? Right. Well I'm T looks at a diagram going to project it / so does this properly express the drawn by a student. fact that there is an image on the contrary of what you have thought?

$252 \mathrm{Al}((\mathrm{T}))$ Yes.

e

$253 \mathrm{~T}$ Does it make clear the fact that it is less luminous?

$254 \mathrm{Al}((\mathrm{T}))$ Yes.

e

$255 \mathrm{~T}$ Yes / there is less light which arrives at the lens

T projects the diagram because we put a mask on it / then what I ask you to do and shows the screen is to represent the the screen I put a real screen there. (a piece of white You put A' and B' because if I mask them you are not paper) which masks going to see them anymore and you should not put the part of the light which passes (2s) look A' B' which are masked / transparency this is the diagram that you should have done unless you put the mask on the bottom which is the same thing (inaudible)

$256 \mathrm{Nl}((\mathrm{T}))$ If we had put the mask (inaudible)

$257 \mathrm{~T} \quad((\mathrm{Nl}))$ Just behind you mean?

$258 \mathrm{Al} \quad((\mathrm{Nl}))$ This doesn't change anything 
$259 \mathrm{Nl} \quad((\mathrm{T}))$ This doesn't change anything (3s)

$260 \mathrm{~T}$ You must put the arrows indeed and then it is better to

T refers to the use two different colours for the points (inaudible) projected diagram otherwise this makes a little (inaudible) (32s) Have you done it? you have correctly placed A'B' because it is masked and then you must get used to call A the point that is on the axis (2s) this is a convention / $\mathrm{A}$ is on the axis B isn't on the axis according to this convention (4s) and then we are going to make a little sentence with a comment

$261 \mathrm{~T} \quad((\mathrm{Nl}))$ First you should finish (inaudible) you have put only one ray there for the moment (8s)

$262 \mathrm{~T} \quad((\mathrm{Cl}))$ If it isn't worthwhile you don't have to write but if you are not sure yet you put that on the contrary to what you have foreseen you observe an image that is not at all cut short by the mask / if this is clear you don't need to write it / but don't make this mistake anymore and then you put this diagram accounts well for the fact that we still observe an image / in spite of $\mathrm{T}$ starts to dictate (in the presence of the mask ( 2 repetitions) $(7 s)$ it is less italics) luminous (inaudible) it is less luminous (2s) do you agree? 
Table 4: possible combinations of modelling processes and semiotic registers

\begin{tabular}{|l|c|c|}
\hline & Natural language register & Schematic register \\
\hline World of objects and events & A & B \\
\hline World of theories and models & C & D \\
\hline
\end{tabular}


Table 5: transcription of episode 4, what is the relation between a beam and a ray? 
$199 \mathrm{~T} \quad((\mathrm{Ale}))$ Then now you should have made a beam as I

have demanded

200 Mat ((Ale)) A beam / what is a ray a ray and a beam

201 Ale ((Mat)) A ray is exactly this / what you have

represented / do a second line / you should do a

second line

$202 \mathrm{~T}$ ((Mat)) It is a set of rays (inaudible) of rays on the

extremity this is a beam

203 Ale ((Mat)) It is the set of two rays

204 Mat ((Ale)) Yes, agreed

$205 \mathrm{~T}$ (inaudible) The children (inaudible)

206 Mat ((Ale)) How did you do that one

207 Ale ((Mat)) Take A prime

208 Mat ((Ale)) No but I don't need it / ah yes right right

They talk while

doing the diagram

209 Ale ((Mat)) Take A prime

210 Mat ((Ale)) This makes fifteen not fourteen / fourteen is at They talk while the other side $(7 \mathrm{~s})$ it is true it is much simpler than the doing the diagram way you said / and I had a good one also at the first

$211 \mathrm{~T} \quad$ A beam of light is a set of rays / these are all the rays T shows the diagram coming from point $\mathrm{A}$ in this case between these two on the blackboard rays

212 Mat ((Mat)) Ok

213 Ale ((Mat)) This yes it is like the billiards when you hit a edge 
214 Mat ((Ale)) Yes but it depends on how hard is the edge /

yes

215 Ale ((Mat)) Yes if you hit it well

216 Mat ((Ale)) Yes 


\section{DIALOGIC/AUTHORITATIVE DISCOURSE AND MODELLING IN A HIGH SCHOOL TEACHING SEQUENCE ON OPTICS}

Christian Buty (1), Eduardo F. Mortimer (2)

(1) UMR ICAR - University Lyon 2 - CNRS - ENS-LSH - ENS Lyon - INRP, France

(2) Universidade Federal de Minas Gerais, Brazil

Postal address: Christian Buty, UMR ICAR, ENS LSH, BP 7000, 15 parvis René Descartes, 69342 LYON CEDEX 7, FRANCE

Email address: Christian.Buty@inrp.fr

Running head: dialogic/authoritative discourse and modelling

\section{Acknowledgements}

This work was supported by CNPq and CAPES (Brazil), CNRS and INRP (France).

The authors wish to express their gratitude to the reviewers on one hand, and on the other hand to Pr. Andrée Tiberghien (CNRS), to Pr. Maria-Pilar Jimenez-Aleixandre (University of Santiago de Compostela), and to Pr. Robin Millar (University of York). 